DOI: http://dx.doi.org/10.22198/rys.2018.71.a811

Artículos

\title{
Déficit de vivienda y satisfacción residencial. Un comparativo entre la frontera norte de México y el país, 2014
}

\author{
Housing deficit and residential satisfaction. \\ A comparison between Mexico's northern border \\ and the rest of the country, 2014 \\ Guadalupe Tejeda Parra* \\ Blanca Esthela Lara Enríquez ${ }^{* *}$
}

Resumen: en este artículo se evaluó y comparó el déficit de vivienda y la satisfacción residencial de la población del país y de la frontera norte de México, en 2014. En las últimas décadas la franja fronteriza ha experimentado procesos de urbanización intensos debido al crecimiento y dinamismo económico y poblacional. La pregunta central fue, ¿existen diferencias en el déficit de vivienda y la satisfacción residencial entre dicha región y el resto del país? La metodología utilizada se basó en el análisis estadístico, con pruebas de hipótesis para probar significancias en la evaluación comparativa de los dos aspectos. En los resultados destacaron las

\footnotetext{
* Licenciada en economía, maestra y doctora en ciencias sociales por El Colegio de Sonora. Departamento de Economía de la Universidad de Sonora. Blvd. Luis Encinas y Rosales s/n, colonia Centro, C. P. 83000, Hermosillo, Sonora, México. Correo electrónico: tejedalupita@hotmail. com

** Doctora en ciencias sociales. Profesora-investigadora del Centro de Estudios del Desarrollo de El Colegio de Sonora. Av. Obregón \#54, colonia Centro, C. P. 83000. Hermosillo, Sonora, México. Teléfono: (662) 259 5300. Correo electrónico: blara@colson.edu.mx
} 
diferencias entre ellos en ambas zonas, que favorecieron, en mayor medida, a la fronteriza.

Palabras clave: vivienda; déficit; satisfacción; crecimiento económico; urbanización.

Abstract: this article evaluated and compared housing deficit and residential satisfaction of population in the country and in Mexico's northern border in 2014. In the last decades, the border strip has undergone an intense urbanization process due to economic and demographic growth and dynamism. The central question was: are there differences concerning housing deficit and residential satisfaction between this region and the rest of the country? The methodology used was based on statistical analysis and the testing of hypothesis in order to test significances when evaluating comparatively the two aspects. Differences between them in both areas stood out in the results, with the border zone being favored to a larger extent.

Key words: housing; deficit; satisfaction; economic growth; urbanization.

Recibido el 4 de agosto de 2016. Aceptado el 17 de febrero de 2017.

\section{Introducción}

El objetivo del artículo fue evaluar y comparar el déficit de vivienda y la satisfacción residencial, tanto en la población de México como en la de la zona fronteriza norte, que en las últimas décadas ha experimentado procesos de urbanización intensos debido al crecimiento y dinamismo económico y poblacional. Se partió de la idea de que el crecimiento económico de la frontera norte ha influido para que haya desigualdades, como las observadas en el déficit y la satisfacción 
con la vivienda en esta zona y en el resto del país. Se contrastaron las carencias en la vivienda en dos dimensiones: cuantitativa y cualitativa, así como los promedios de satisfacción residencial para el país y la frontera; las diferencias en ambos aspectos en las dos regiones fueron favorables, en mayor medida, para esta última.

El artículo contiene una introducción y siete apartados; en el primero se analizan los conceptos de déficit de vivienda y la satisfacción residencial, con base en la revisión de la literatura sobre el tema, que sirve de base para el planteamiento. En el segundo se relaciona el desarrollo regional con las políticas habitacionales, se rescata el carácter público de la vivienda, y se establece cómo las políticas públicas han influido en los procesos de desarrollo regional y urbano. Asimismo, presenta a la frontera norte de México (FNM) dentro de los procesos de urbanización, y recrea el escenario de crecimiento económico que ha tenido en las últimas décadas. El tercero contiene la metodología utilizada para establecer significancias estadísticas en la evaluación comparativa del déficit y la satisfacción, además analiza la fuente de información, que es la Encuesta nacional de ingresos y gastos de los hogares (ENIGH) de 2014, realizada por el Instituto Nacional de Estadística y Geografía, INEGI (2015b). En el cuarto se presenta una caracterización de los hogares en México y la FNM, que brinda un contexto de las viviendas en las dos zonas. El quinto se dedica al análisis comparativo del déficit cuantitativo, cualitativo y la satisfacción residencial en México y en los estados de la FNM. En el sexto se examinan los resultados y en el último se presentan las conclusiones.

\section{Déficit de vivienda y satisfacción residencial}

La valoración de la vivienda, como componente importante de la vida de las personas, es una dimensión desde la cual se han configurado reflexiones y aportes diversos y variados para estimarla y comprenderla. Del conjunto de necesidades humanas primarias, la vivienda es una de las primordiales y de las más valoradas por la población (Arriagada 2003; Boils 2004; Consejo Nacional de Evaluación de la Política de Desarrollo Social, CONEVAL 2010; González 2013; KunzBolaños y Romero-Vadillo 2008; Palomares 2008). 
La Constitución Política de los Estados Unidos Mexicanos contempla, en su artículo $4^{\circ}$, el derecho de toda familia a disponer de una vivienda digna y decorosa. En la práctica no resulta fácil identificar los parámetros adecuados para operativizar esta definición que, para Kunz-Bolaños y Romero-Vadillo (2008), implica un enfoque relativista, en tanto se refiere a una construcción inserta en un conjunto de factores que la determinan: el cultural, los cambios en las necesidades sociales, las tradiciones, la ideología y el hábitat. En estas condiciones, se requiere construir la conceptualización desde un contexto sociocultural determinado.

La definición de digno y decoroso tiene su contraparte en el concepto de déficit habitacional, en cuyo análisis, de manera general, se pueden rescatar dos aspectos: cuantitativo y cualitativo; el primero está relacionado con la cantidad o la expansión del número de viviendas, y el segundo con la calidad de éstas. Para Kunz-Bolaños y Romero-Vadillo (2008), el déficit cuantitativo se refiere al número de viviendas que se requieren para satisfacer las necesidades de las familias en dos situaciones: cuando no cuentan con una, o cuando la que tienen no cubre los requerimientos mínimos de protección y desarrollo para sus habitantes. El déficit cualitativo describe a las viviendas que carecen de las cualidades para ser consideradas dignas y decorosas.

Arriagada (2003) también distingue dos tipos de requerimientos habitacionales, el relacionado con mejorar la calidad (cualitativo), y el relacionado con la expansión (cuantitativo). De acuerdo con este autor, el último aspecto representa la cantidad de viviendas que la sociedad debe construir para satisfacer las necesidades acumuladas, mientras que el primero se refiere a las que se deben mejorar en cuanto a los componentes materiales, servicios o espacios.

Palomares (2008) propone analizar el acondicionamiento de la vivienda desde una evaluación normativa en tres aspectos: a) las características de la construcción; b) los servicios públicos con los que cuenta y c) la disponibilidad de espacios para las actividades cotidianas. Desde esta perspectiva, el acondicionamiento se contempla como un componente de la protección mínima, que no varía conforme cambian los patrones tecnológicos. Argumenta que es importante 
medir las características de la vivienda a partir de dicha cobertura, y no de los recursos disponibles en las localidades.

De acuerdo con la Secretaría de Desarrollo Social, SEDESOL (s/f), el déficit y los problemas de la vivienda están cimentados en el contexto rural-urbano. Hay grandes contrastes entre las ciudades (urbanas), que se han erigido como columnas del desarrollo en cada entidad, y las comunidades (rurales), que han sido relegadas de las dinámicas estatales; en las ciudades también está presente la disparidad. Se reconoce que existe un rezago habitacional cuantitativo y cualitativo en las poblaciones de la frontera; el primero alude a la falta de vivienda o a las que requieren sustituirse por la mala calidad de sus materiales, mientras que el segundo apunta a las que, debido a su deterioro, no satisfacen un mínimo de bienestar para sus ocupantes. Ubica que este rezago es mayor en las localidades urbanas de la frontera.

Para el CONEVAL (2010), las personas en situación de carencia son las que habitan viviendas con al menos una de las características siguientes: a) pisos de tierra; b) techo de lámina de cartón o de desechos; c) muros de embarro o bajareque: carrizo, bambú o palma; lámina de cartón, metálica o asbesto o material de desecho y d) hay más de 2.5 personas por cuarto (hacinamiento). La Comisión Nacional de Vivienda (CONAVI) establece dos dimensiones en el indicador de calidad de la vivienda: el material de construcción y los espacios (CONOREVI 2011).

Para diseñar y evaluar la vivienda, como parte de las políticas públicas, es primordial estimar el déficit habitacional. Sin embargo, la política actual del país en la materia sobrepone el factor cuantitativo al cualitativo (Arriagada 2003; Palomares 2008; Kunz-Bolaños y Romero-Vadillo 2008), lo que ha favorecido la creación de viviendas nuevas y descuida la calidad de las existentes. Arriagada (2003) plantea la necesidad de implementar una política habitacional equilibrada, la define como aquélla que, desde su diseño, toma en cuenta aspectos que involucran la construcción de viviendas nuevas, como los relacionados con la consolidación y reparación de las existentes.

Por otra parte, la satisfacción residencial se ha abordado, en mayor medida, desde la psicología ambiental, que la relaciona con los sentimientos favorables o desfavorables de los habitantes hacia las características del ambiente físico y sus problemáticas, que Moyano (2009) 
la define como el grado de afecto que produce vivir en un contexto determinado, y engloba tres aspectos: la satisfacción con la vivienda, con el conjunto y con el barrio. El conjunto se refiere a las viviendas que comparten aspectos semejantes de construcción, como ser parte del mismo proyecto o momento. El barrio agrupa a conjuntos habitacionales con dimensiones geográficas semejantes. De acuerdo con esta directriz, una vivienda está inmersa en un conjunto, que a su vez pertenece a un barrio.

Amérigo (citado en Moyano 2009) define la satisfacción residencial como la distancia que hay entre las características reales del ambiente residencial y las deseadas por sus habitantes. Por tanto, parte de dos contextos: la situación real observada en las viviendas y la deseada, por lo que ambos se comparan al momento de valorar dicha satisfacción.

Para definir la satisfacción residencial, Andrade et al. (2007) establecen tres escalas territoriales: a) el microsistema, relación de la familia y la vivienda; b) el mesosistema, relación entre los vecinos y el entorno inmediato y c) el macrosistema, relación de la comunidad con el conjunto residencial, que interactúan con el habitante y su entorno, y configuran el agrado o desagrado por cada uno, expresados en la satisfacción residencial.

Para Aragonés y Amérigo (1987, 135), la satisfacción residencial se refiere a un criterio subjetivo y la definen como "la actitud o el afecto que produce el hecho de vivir en un determinado contexto". Al tener en cuenta que las personas comparan la percepción de su entorno con sus estándares de la vivienda, el barrio y el vecindario. Por lo tanto, la satisfacción residencial varía en relación con el contexto físico del hogar, así como con las necesidades y aspiraciones de las personas y las relaciones con los vecinos.

Ibarra et al. (2016) consideran que la satisfacción con la colonia tiene influencia en la salud, el bienestar y la calidad de vida de las personas, que incluye la percepción de los habitantes y el contexto de la colonia. El primer aspecto hace alusión a un elemento individual, mientras que el segundo es uno agregado, que puede hacer más atractivo vivir en un lugar determinado. 


\section{Desarrollo regional y políticas habitacionales}

El carácter público del tema de la vivienda incluye la intervención y la participación activa del Estado, los retos y los desafíos actuales en la materia obligan a diseñar políticas públicas eficaces para atender la problemática. Debido a su importancia, la vivienda se ubica en el centro de las políticas sociales, pues se trata de una necesidad humana difícil de satisfacer por cualquier otra vía, como por ejemplo la alimentación, en la que participan las organizaciones de caridad (KunzBolaños y Romero-Vadillo 2008).

En México, el papel del Banco Mundial ha sido primordial en el diseño y financiamiento de las políticas de vivienda pública (Boils 2004). El segundo lugar lo ocupan las agencias de gobierno, el Instituto del Fondo Nacional de la Vivienda para los Trabajadores (INFONAVIT) y el Fondo de la Vivienda del Instituto de Seguridad y Servicios Sociales de los Trabajadores del Estado (FOVISSSTE), creados en 1972, y los organismos financieros públicos principales que otorgan créditos a los trabajadores. La CONAVI coordina la promoción habitacional y es responsable del Programa Nacional de Vivienda, además se encarga de aplicar y cuidar que se cumplan los objetivos y metas del gobierno federal en la materia.

El financiamiento de la vivienda ha influido en la configuración del desarrollo regional en México (Monkkonen 2009). Las restricciones en los préstamos para vivienda y su asignación exclusiva para los empleados formales y asalariados, que representan casi la mitad de la fuerza laboral, ha repercutido en el desarrollo urbano, debido a que la mayoría de la inversión en esta materia se encuentra en las ciudades y regiones con mayor empleo y salario, lo que ha favorecido a los centros manufactureros del norte del país. Para el autor, el sistema de financiamiento de la vivienda influye en la estructuración demográfica de la población, las ciudades que reciben mayores recursos económicos crecen más rápido, lo que provoca segregación.

Según Palomares (2008), analizar la vivienda en un marco regional permite explicar ciertos patrones de crecimiento y desarrollo, y si la región logra mejorar las condiciones de vida de sus habitantes, en particular el acondicionamiento de la vivienda, que es uno de sus componentes destacados. 
De acuerdo con Boils (2004), la política habitacional implementada en México ha tenido efectos negativos en los sectores sociales de menores ingresos, pues existen mecanismos gubernamentales de exclusión en el gasto social en la materia. El argumento se sustenta en que los préstamos concedidos por organismos internacionales, convertidos en las fuentes principales de ingreso, influyen en las decisiones del gobierno sobre el diseño y la orientación de las políticas públicas, que se compromete a seguir criterios, procedimientos y plazos asignados en los contratos. El país receptor del préstamo está obligado a adoptar políticas de gasto social que, muchas veces, afianzan mecanismos excluyentes, "muy pocos créditos para adquisición de vivienda en México se proporcionan a familias cuyos ingresos están por debajo de los cinco salarios mínimos (poco más de 6000 pesos mensuales). Este nivel de ingresos deja fuera a más de $75 \%$ de las familias del país" (Boils 2004, 348).

\section{Urbanización y crecimiento económico en la frontera norte de México}

En 2008, por primera vez en la historia, la población mundial residente en áreas urbanas superó 50 por ciento, lo que las convirtió en el hábitat dominante de la humanidad. Las repercusiones de este cambio en el desarrollo humano son enormes, el crecimiento económico y la urbanización son dos procesos ligados; un crecimiento acelerado lleva a una urbanización rápida, que si bien puede ayudar a superar la pobreza también a originar problemas sociales, económicos y ambientales, y convertirse en amenaza para el desarrollo sostenible (Comisión Económica para América Latina, CEPAL 2014).

En América Latina, la tasa de urbanización llegó a 50 por ciento a principios de la década de 1960, y avanzó aceleradamente hasta alcanzar 80, en 2013. En sólo 50 años se rebasaron tres umbrales (60, 70 y 80 por ciento), y los países dieron un "triple salto". En 2013, México llegó a una tasa de urbanización de 79 por ciento, estuvo entre las 13 naciones latinoamericanas con tasas superiores a 70 por ciento; Brasil y México fueron las más pobladas de la región, alcanzaron 200 y 120 millones de habitantes, en 2013, y 33 y 20 por 
ciento de la población y, sin ser las más urbanizadas, contribuyeron con más de la mitad del crecimiento demográfico urbano desde los años sesenta (Wenze 2014). La frontera norte de México está formada por Baja California, Sonora, Chihuahua, Coahuila, Nuevo León y Tamaulipas, constituye más de 3 mil kilómetros, comprende cerca de 40 por ciento de la superficie total del país y colinda con California, Arizona, Nuevo México y Texas, en Estados Unidos. Dichas entidades mexicanas son centros de atracción a donde la población llega para establecerse, en los últimos años experimentaron dinámicas demográficas sobresalientes debido a procesos migratorios intensos, derivados de una mayor oferta de trabajo. En 1960, en los seis estados fronterizos vivía 15.9 por ciento de la población nacional, en 1990 el porcentaje fue de 16.3, en 2010 alcanzó 17.7, ${ }^{1}$ y en 2014, llegó a 18.1 INEGI (2015b).

La tendencia mundial es que la población se concentre en las ciudades, lo que también se observó en los estados de la frontera norte en 2014. Casi tres cuartas partes de los residentes de la zona (71.4 por ciento) vive en urbes de más de 100 mil personas, en el país la concentración es menor, estas ciudades congregan a la mitad de los habitantes. En las últimas décadas, las tasas de crecimiento demográfico en la zona han superado a las nacionales. Entre 1970 y 1980 el aumento de la población en México superó ligeramente al de la frontera, 3.3 y 3.1 respectivamente. Después el dinamismo fue inverso; entre 1990 y el año 2000, fue de 2.3 por ciento anual en la frontera, contra 1.8 en el país. En la misma década, cinco de las seis entidades fronterizas crecieron a tasas superiores a la nacional. ${ }^{2}$

Desde la entrada en vigor del Tratado de Libre Comercio con América del Norte, el crecimiento económico de la frontera norte ha sido sobresaliente, en relación con el del resto de México debido, entre otras razones, a las diferencias salariales, que se agudizaron con la apertura comercial, que han favorecido a la región (Hanson 2003). El dinamismo de la frontera no es homogéneo, existen disparidades importantes en los seis estados y entre ellos; se trata de procesos he-

1 Cálculos propios, con base en varios censos y conteos de población y vivienda (INEGI 19702010).

2 Cálculos propios, con base en varios censos y conteos de población y vivienda (INEGI 19702010). 
terogéneos donde se encuentran municipios de gran dinamismo e índices elevados de crecimiento, y otros que han quedado relegados de la dinámica económica (Dávila 2008; Mendoza 2010).

Existen ciudades y zonas urbanas insertas en la producción mundial con procesos tecnológicos avanzados, y localidades y áreas rurales excluidas de éstos. También hay contrastes sociales en infraestructura, servicios públicos, vivienda y su equipamiento adecuado, hay zonas solventes y otras que carecen de lo mínimo necesario para un desarrollo social armónico (SEDESOL s/f; Guillén 2007; Acosta et al. 2012).

Los procesos de urbanización acelerados de las economías fronterizas han generado problemáticas inéditas para la vida en las ciudades, y desafíos complejos para el desarrollo urbano. La premisa de que en estos espacios la población encontraría mejores condiciones de trabajo y, en consecuencia, de bienestar no necesariamente se cumple, pero el tema constituye una oportunidad para enfocar el análisis y las políticas públicas en los aspectos relacionados con el mejoramiento de las condiciones de vida de la población, como el caso de la vivienda, valorada como un componente importante del bienestar social (Boltvinik 1992). Según Palomares (2008), la concentración demográfica de la frontera norte en las últimas décadas no ha significado un mayor acondicionamiento de la vivienda en términos generales, aunque se pueden rescatar resultados de éxito.

El aumento demográfico fronterizo provocó mayor demanda de vivienda, que no se ha logrado solventar. Según la SEDESOL (s/f), existen dos problemas relacionados con el tema: a) la incapacidad económica de los trabajadores para comprar una vivienda, debido al alto costo del suelo y a la pérdida del poder adquisitivo salarial ${ }^{3}$ y b) la invasión de predios, que ha ocasionado una autoconstrucción elevada y falta de terrenos disponibles para una planificación ordenada en las ciudades. En las urbes fronterizas, las colonias populares y las de la periferia son las más afectadas.

3 Este fenómeno se observa a pesar de que en las zonas fronterizas los ingresos son mayores. 


\section{Metodología}

Con la metodología cuantitativa se evaluó y comparó el déficit de vivienda y la satisfacción residencial en la FNM y en México en tres componentes: déficit cuantitativo, déficit cualitativo y satisfacción residencial. El primero se define como la necesidad de tener vivienda; involucra a viviendas que no cumplen con un mínimo necesario de condiciones, expresadas en seis tipos de rezago: a) en las que existe más de un hogar; b) las que están en cuarto de azotea; c) los locales no construidos para habitación; d) aquéllas con antigüedad mayor de 50 años; e) las que carecen de cocina y f) las que no tienen baño.

El déficit cualitativo se refiere a las viviendas con equipamiento escaso, con algún tipo de problema de acondicionamiento. Se expresa en tres tipos de carencias: a) de espacios, se refleja en hacinamiento, falta de cocina y de sanitario exclusivo; b) de servicios, incluye abastecimiento de agua, drenaje, eliminación de basura, disponibilidad de energía eléctrica y tipo de combustible para preparar alimentos y c) de materiales de construcción en paredes, techos y pisos. La satisfacción residencial es la percepción autoreportada que los habitantes expresan sobre su satisfacción con la vivienda y el vecindario.

La fuente de información primaria es la ENIGH de 2014 (INEGI 2015b), con representatividad nacional y por entidad federativa, de la que se utilizó el módulo de condiciones socioeconómicas, que en el cuestionario ofrece información de las características y el equipamiento de las viviendas en el país, y el módulo de bienestar autorreportado (BIARE), que contiene la opinión de las personas sobre su bienestar y satisfacción con la vida, así como con la vivienda y el vecindario.

El análisis del país se hizo con base en 39274 cuestionarios que son los microdatos del BIARE, sólo respondió una persona por vivienda y no se repitieron. Para analizar la FNM se seleccionaron 7 112 cuestionarios de Baja California, Sonora, Chihuahua, Coahuila, Nuevo León y Tamaulipas. Se utilizó la variable factor de expansión ofrecida por la ENIGH como ponderador de la muestra.

Los porcentajes o promedios de cada dimensión se elaboraron con el análisis estadístico y se probó la significancia en las diferencias, con base en pruebas de hipótesis t-calculada, para el caso de diferencia 
de proporciones, y z-calculada para el de diferencia de medias, con el fin de dar certeza estadística a los resultados. ${ }^{4} \mathrm{El} \mathrm{manejo} \mathrm{de} \mathrm{la} \mathrm{base}$ de datos y la presentación de gráficas y resultados se hicieron con los paquetes STATA 16.0 y Excel.

\section{Caracterización de los hogares en México y en la frontera norte}

En este apartado se presentan algunas características que definen y contextualizan las viviendas en México y en la frontera. La variable de parentesco, que el INEGI $(2011,49)$ define como "el vínculo o lazo de unión que existe entre cada uno de los residentes de la vivienda con la jefa/e de la misma por consanguinidad, matrimonio, adopción, afinidad o costumbre”, permite clasificar a los hogares en familiares y no familiares, y así se obtienen otras cinco. Los hogares

Figura 1. Clasificación de los hogares censales, 2014

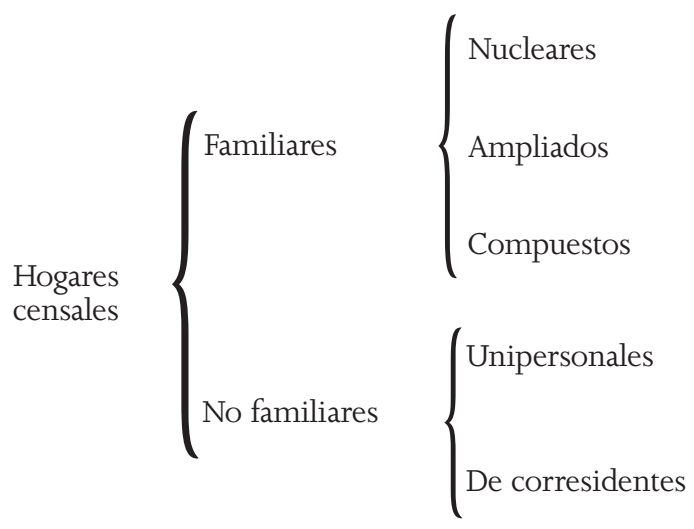

Fuente: INEGI (2015b).

4 En todas las pruebas de hipótesis se utiliza un nivel de confianza estadística de 95 por ciento, $\alpha=0.05$. 
familiares se dividen en: a) nuclear, el constituido por un solo grupo familiar primario; b) ampliado, el formado por el/la jefe/a y su familia primaria más otros grupos familiares o parientes y c) compuesto, el integrado por un hogar nuclear o ampliado con personas sin parentesco con el/la jefe/a. Las categorías de los hogares no familiares son: a) el unipersonal, de una persona, que es el/la jefe/a y b) el de corresidentes, de dos o más personas que no tienen parentesco con el/la jefe/a (véase Figura 1).

En estas clasificaciones quedan reflejados los nuevos escenarios que configuran las familias en México. Los mayores porcentajes corresponden a los hogares familiares nucleares, seguidos por los ampliados, además se observan participaciones importantes de los compuestos y de los no familiares, en particular los unipersonales (véase Figura 2).

Figura 2. Clasificación de los hogares según tipo (\%), 2014

\begin{tabular}{|c|c|c|c|c|}
\hline Categoría & México & $\begin{array}{c}\text { Frontera } \\
\text { norte }\end{array}$ & Prueba de hipótesis & $\begin{array}{c}\text { Significancia } \\
\text { estadística }\end{array}$ \\
\hline Nuclear & 65.0 & 66.3 & $\left(\mathrm{z}_{\text {calculada }}=-2.11, \mathrm{z}_{\text {crítica }}= \pm 1.96\right)$ & Diferencia \\
\hline Ampliado & 23.5 & 22.9 & $\left(\mathrm{z}_{\text {calculada }}=1.09, \mathrm{z}_{\text {crítica }}= \pm 1.96\right)$ & No diferencia \\
\hline Compuesto & 0.7 & 0.7 & $\left(\mathrm{z}_{\text {calculada }}=0, \mathrm{z}_{\text {crítica }}= \pm 1.96\right)$ & No diferencia \\
\hline Unipersonal & 10.2 & 9.8 & $\left(\mathrm{z}_{\text {calculada }}=1.02, \mathrm{z}_{\text {crítica }}= \pm 1.96\right)$ & No diferencia \\
\hline Corresidente & 0.5 & 0.3 & $\left(\mathrm{z}_{\text {calculada }}=2.27, \mathrm{z}_{\text {crítica }}= \pm 1.96\right)$ & Diferencia \\
\hline
\end{tabular}

Fuente: elaboración propia, con base en el INEGI (2015b).

El INEGI (2015a) clasifica las viviendas con base en las características socioeconómicas de quienes las habitan, de aspectos físicos y del equipamiento. En la frontera norte de México, 6.3 por ciento de los hogares tenían un nivel socioeconómico bajo, y en el país el porcentaje era de 18. El extremo contrario también favorecía a la frontera 
norte, 15.8 por ciento de las viviendas con nivel alto, y sólo 9.3 en el país (véase Figura 3).

Figura 3. Clasificación de las viviendas según estrato socioeconómico (\%), 2014

\begin{tabular}{|c|c|c|c|c|}
\hline Categoría & México & $\begin{array}{c}\text { Frontera } \\
\text { norte }\end{array}$ & Prueba de hipótesis & $\begin{array}{c}\text { Significancia } \\
\text { estadística }\end{array}$ \\
\hline Bajo & 18.0 & 6.3 & $\left(\mathrm{z}_{\text {calculada }}=24.63, \mathrm{z}_{\text {crítica }}= \pm 1.96\right)$ & Diferencia \\
\hline Medio bajo & 50.4 & 43.0 & $\left(\mathrm{z}_{\text {calculada }}=11.48, \mathrm{z}_{\text {crítica }}= \pm 1.96\right)$ & Diferencia \\
\hline Medio alto & 22.3 & 35.0 & $\left(\mathrm{z}_{\text {calculada }}=-22.99, \mathrm{z}_{\text {crítica }}= \pm 1.96\right)$ & Diferencia \\
\hline Alto & 9.3 & 15.8 & $\left(\mathrm{z}_{\text {calculada }}=-16.59, \mathrm{z}_{\text {crítica }}= \pm 1.96\right)$ & Diferencia \\
\hline
\end{tabular}

Fuente: elaboración propia, con base en el INEGI (2015b).

La vivienda está relacionada con la agenda urbana (Palomares 2008). En México, las localidades rurales son las menores de 2500 habitantes (INEGI 2015a); con base en este criterio, casi 90 por ciento de los residentes de la frontera norte habita en comunidades urbanas, contra 78.5 del país. Sólo 10.1 por ciento de la población de la frontera vive en localidades menores de 2500 personas, en cambio, en el país el porcentaje alcanza 21.6 (véase Figura 4).

Figura 4. Concentración de la población por tamaño de localidad, 2014

\begin{tabular}{|c|c|c|c|c|}
\hline $\begin{array}{c}\text { Número de } \\
\text { habitantes }\end{array}$ & México & $\begin{array}{c}\text { Frontera } \\
\text { norte }\end{array}$ & Prueba de hipótesis & $\begin{array}{c}\text { Significancia } \\
\text { estadística }\end{array}$ \\
\hline 100000 y más & 49.9 & 71.4 & $\left(\mathrm{z}_{\text {calculada }}=-33.43, \mathrm{z}_{\text {crítica }}= \pm 1.96\right)$ & Diferencia \\
\hline 15000 a 99999 & 14.5 & 12.3 & $\left(\mathrm{z}_{\text {calculada }}=4.89, \mathrm{z}_{\text {crítica }}= \pm 1.96\right)$ & Diferencia \\
\hline 2500 a 14999 & 14.0 & 6.2 & $\left(\mathrm{z}_{\text {calculada }}=18.11, \mathrm{z}_{\text {crítica }}= \pm 1.96\right)$ & Diferencia \\
\hline Menos de 2500 & 21.6 & 10.1 & $\left(\mathrm{z}_{\text {calculada }}=22.37, \mathrm{z}_{\text {crítica }}= \pm 1.96\right)$ & Diferencia \\
\hline
\end{tabular}

Fuente: elaboración propia, con base en el INEGI (2015b). 
Contar con una vivienda propia representa un patrimonio familiar (INEGI 2011), la distribución de la posesión legal de ésta revela el alto porcentaje de las que no son propias, en México (38.5), pero en la frontera el dato es mayor, llega a 46.6. Sin embargo, en la FNM 18.1 por ciento de viviendas se está pagando, contra 8.4 del país. Si a este dato se suma el de vivienda propia, asciende a 61.5 por ciento en ambas zonas (véase Figura 5).

Figura 5. Tipo de tenencia de la vivienda (\%), 2014

\begin{tabular}{|c|c|c|c|c|}
\hline Categoría & México & $\begin{array}{c}\text { Frontera } \\
\text { norte }\end{array}$ & Prueba de hipótesis & $\begin{array}{c}\text { Significancia } \\
\text { estadística }\end{array}$ \\
\hline Rentada & 13.9 & 14.4 & $\left(\mathrm{z}_{\text {calculada }}=-1.11, \mathrm{z}_{\text {crítica }}= \pm 1.96\right)$ & No diferencia \\
\hline Prestada & 14.2 & 11.4 & $\left(\mathrm{z}_{\text {calculada }}=6.30, \mathrm{z}_{\text {crítica }}= \pm 1.96\right)$ & Diferencia \\
\hline $\begin{array}{c}\text { Propia, pero } \\
\text { la están } \\
\text { pagando }\end{array}$ & 8.4 & 18.1 & $\left(\mathrm{z}_{\text {calculada }}=-25.21, \mathrm{z}_{\text {crítica }}= \pm 1.96\right)$ & Diferencia \\
\hline Propia & 61.5 & 53.4 & $\left(\mathrm{z}_{\text {calculada }}=12.84, \mathrm{z}_{\text {crítica }}= \pm 1.96\right)$ & Diferencia \\
\hline $\begin{array}{c}\text { Intestada o } \\
\text { en litigio }\end{array}$ & 1.4 & 2.0 & $\left(\mathrm{z}_{\text {calculada }}=-3.84, \mathrm{z}_{\text {crítica }}= \pm 1.96\right)$ & Diferencia \\
\hline $\begin{array}{c}\text { Otra } \\
\text { situación }\end{array}$ & 0.6 & 0.8 & $\left(\mathrm{z}_{\text {calculada }}=-1.96, \mathrm{z}_{\text {crítica }}= \pm 1.96\right)$ & No diferencia \\
\hline
\end{tabular}

Fuente: elaboración propia, con base en el INEGI (2015b).

La mayoría de las personas utiliza recursos propios para pagar, construir, ampliar o modificar la vivienda, en México 46.4 por ciento y en la FNM 38.1. El financiamiento del INFONAVIT, el FOVISSSTE o del Fondo Nacional de Habitaciones Populares (FONHAPO) para obtener una vivienda es mayor en la frontera, 22.6 por ciento, que en el país, 12.0 (véase Figura 6). 
Figura 6. Tipo de financiamiento de la vivienda (\%), 2014

\begin{tabular}{|c|c|c|c|c|}
\hline Categoría & México & $\begin{array}{c}\text { Frontera } \\
\text { norte }\end{array}$ & Prueba de hipótesis & $\begin{array}{c}\text { Significancia } \\
\text { estadística }\end{array}$ \\
\hline $\begin{array}{c}\text { Crédito del } \\
\text { INFONAVIT, }\end{array}$ & 12.0 & 22.6 & $\left(\mathrm{z}_{\text {calculada }}=-23.97, \mathrm{z}_{\text {crítica }}= \pm 1.96\right)$ & Diferencia \\
$\begin{array}{c}\text { FOVISSSTE o } \\
\text { FONHAPO }\end{array}$ & 5.4 & $\left(\mathrm{z}_{\text {calculada }}=-7.23, \mathrm{z}_{\text {crítica }}= \pm 1.96\right)$ & Diferencia \\
\hline $\begin{array}{c}\text { Crédito de un } \\
\text { banco, sociedad } \\
\text { financiera de } \\
\text { objeto limitado } \\
\text { o caja de ahorro }\end{array}$ & 3.6 & 1.6 & $\left(\mathrm{z}_{\text {calculada }}=0, \mathrm{z}_{\text {crítica }}= \pm 1.96\right)$ & No diferencia \\
\hline $\begin{array}{c}\text { Crédito de otra } \\
\text { institución }\end{array}$ & 1.6 & 0.8 & $\left(\mathrm{z}_{\text {calculada }}=6.97, \mathrm{z}_{\text {crítica }}= \pm 1.96\right)$ & Diferencia \\
\hline $\begin{array}{c}\text { Préstamo de un } \\
\text { familiar, amigo } \\
\text { o prestamista }\end{array}$ & 2.0 & 38.1 & $\left(\mathrm{z}_{\text {calculada }}=12.94, \mathrm{z}_{\text {crítica }}= \pm 1.96\right)$ & Diferencia \\
\hline $\begin{array}{c}\text { Recursos } \\
\text { propios }\end{array}$ & 46.4 & & \\
\hline
\end{tabular}

Nota: los porcentajes no suman 100 por ciento debido a que hubo personas que no utilizaron alguna de las categorías analizadas o no declararon haberlo hecho.

Fuente: elaboración propia, con base en el INEGI (2015b).

La edad promedio del jefe de los hogares en México y en la FNM supera los 48 años, no hubo diferencias estadísticas significativas en este indicador, y tampoco en los promedios de educación de los jefes del hogar en México y la FNM; cuentan con primaria completa y al menos un año de secundaria (véase Figura 7).

Figura 7. Años promedio de edad y educación del jefe del hogar, 2014

\begin{tabular}{|c|c|c|c|c|}
\hline Categoría & México & $\begin{array}{c}\text { Frontera } \\
\text { norte }\end{array}$ & Prueba de hipótesis & $\begin{array}{c}\text { Significancia } \\
\text { estadística }\end{array}$ \\
\hline $\begin{array}{c}\text { Edad del jefe } \\
\text { del hogar }\end{array}$ & 48.8 & 48.7 & $\left(\mathrm{z}_{\text {calculada }}=0.15, \mathrm{z}_{\text {crítica }}= \pm 1.96\right)$ & No diferencia \\
\hline $\begin{array}{c}\text { Educación del } \\
\text { jefe del hogar }\end{array}$ & 8.2 & 7.9 & $\left(\mathrm{z}_{\text {calculada }}=0.85, \mathrm{z}_{\text {crítica }}= \pm 1.96\right)$ & No diferencia \\
\hline
\end{tabular}

Fuente: elaboración propia, con base en el INEGI (2015b). 


\section{Análisis comparativo del déficit y la satisfacción residencial en México y en la frontera norte}

\section{Déficit cuantitativo}

El INEGI $(2011,144)$ define la vivienda como el "espacio delimitado generalmente por paredes y techos de cualquier material, con entrada independiente, que se construyó para la habitación de personas, o que al momento del levantamiento censal se utiliza para vivir", y hogar es la "unidad formada por una o más personas, vinculadas o no por lazos de parentesco, que residen habitualmente en la misma vivienda particular". Las viviendas pueden estar conformadas por uno o más hogares; este es el caso que aborda el déficit cuantitativo.

Desde sus inicios, los censos levantados en México consideran varias condiciones para definir el significado de hogar, siempre tomando en cuenta el concepto de familia como el grupo social básico de la sociedad, que es la raíz de la definición. Por ejemplo, el censo de 1970 se apoya en la residencia habitual para definir la familia censal, mientras que los de 1980 al año 2000 utilizan el gasto común como eje para definir al hogar (INEGI 2011). En esta definición, fundamentada en el gasto, es fácil emplear el concepto de hogar extra como un indicador de rezago, pues la distinción de hogares en el interior de la vivienda, basados en el gasto, es claramente distinta, ya que el INEGI define este tipo de hogar cuando en una misma vivienda existen dos o más unidades de gasto.

A partir del censo de 2010 se abandonó la distinción de los hogares por el gasto común, debido a que muchos núcleos familiares rebasan la idea del gasto compartido en alimentación, lo que evidencia que hay formas distintas de organización. La definición de hogar queda delimitada "al núcleo de residentes de la vivienda con independencia de sus vínculos de parentesco" (INEGI 2011, 125), el hogar censal que se reconoce a partir del censo de $2010^{5}$ es equivalente al número de viviendas.

5 Y, por tanto, en la ENIGH 2014, en la que se basó este artículo. 
Aun así, el INEGI recoge una variable relacionada con la condición de residencia de la madre o el padre, con el fin de distinguir los núcleos familiares dentro de cada vivienda. Así, se puede clasificar y codificar el número de hogares en cada una, es decir, situaciones donde en una misma vivienda resida más de un hogar, en relación con los lazos de parentesco y no al gasto compartido como se había utilizado antes.

Con base en las clasificaciones nuevas del INEGI en la definición de hogar, esta variable recoge el primer aspecto por considerar en relación con el déficit cuantitativo, ya que representa a las familias que no cuentan con casa propia por lo que ocupan la de otra familia. Existe una diferencia en el total de hogares en las viviendas entre México y la FNM, según este indicador en la misma residen dos o tres hogares, pero en el país, a diferencia de lo que sucede en la FNM, se pueden encontrar cuatro o cinco en una misma vivienda (véase Figura 8).

Figura 8. Total de hogares en la vivienda (\%), 2014

\begin{tabular}{|c|c|c|c|c|}
\hline $\begin{array}{c}\text { Número de } \\
\text { hogares }\end{array}$ & México & $\begin{array}{c}\text { Frontera } \\
\text { norte }\end{array}$ & Prueba de hipótesis & $\begin{array}{c}\text { Significancia } \\
\text { estadística }\end{array}$ \\
\hline Uno & 96.7 & 97.9 & $\left(\mathrm{z}_{\text {calculada }}=-5.35, \mathrm{z}_{\text {crítica }}= \pm 1.96\right)$ & Diferencia \\
\hline Más de uno & 3.3 & 2.1 & $\left(\mathrm{z}_{\text {calculada }}=5.36, \mathrm{z}_{\text {crítica }}= \pm 1.96\right)$ & Diferencia \\
\hline
\end{tabular}

Fuente: elaboración propia, con base en el INEGI (2015b).

Al déficit cuantitativo se agrega la variable tipo de vivienda, con cinco categorías, de las cuales se seleccionaron las de cuarto de azotea y los locales no construidos para habitación (véase Figura 9). Ambas son parte del rezago habitacional, pues se consideran alojamientos inadecuados para las funciones de una vivienda. No hay diferencia significativa entre los porcentajes de la FNM y el país en ambas categorías. 
Figura 9. Tipo de vivienda (\%), 2014

\begin{tabular}{|c|c|c|c|c|}
\hline Categoría & México & $\begin{array}{c}\text { Frontera } \\
\text { norte }\end{array}$ & Prueba de hipótesis & $\begin{array}{c}\text { Significancia } \\
\text { estadística }\end{array}$ \\
\hline $\begin{array}{c}\text { Casa } \\
\text { independiente }\end{array}$ & 91.5 & 95.5 & $\left(\mathrm{z}_{\text {calculada }}=-11.51, \mathrm{z}_{\text {crítica }}= \pm 1.96\right)$ & Diferencia \\
\hline $\begin{array}{c}\text { Departamento } \\
\text { en edificio }\end{array}$ & 4.8 & 2.0 & $\left(\mathrm{z}_{\text {calculada }}=10.62, \mathrm{z}_{\text {crítica }}= \pm 1.96\right)$ & Diferencia \\
\hline $\begin{array}{c}\text { Vivienda en } \\
\text { vecindad }\end{array}$ & 2.8 & 1.4 & $\left(\mathrm{z}_{\text {calculada }}=6.84, \mathrm{z}_{\text {crítica }}= \pm 1.96\right)$ & Diferencia \\
\hline $\begin{array}{c}\text { Vivienda en } \\
\text { cuarto de azotea }\end{array}$ & 0.1 & 0.1 & $\left(\mathrm{z}_{\text {calculada }}=0, \mathrm{z}_{\text {crítica }}= \pm 1.96\right)$ & No diferencia \\
\hline $\begin{array}{c}\text { Local no } \\
\text { construido para } \\
\text { habitación }\end{array}$ & 0.8 & 0.8 & $\left(\mathrm{z}_{\text {calculada }}=0, \mathrm{z}_{\text {crítica }}= \pm 1.96\right)$ & No diferencia \\
\hline No especificado & 0.1 & 0.2 & $\left(\mathrm{z}_{\text {calculada }}=-2.28, \mathrm{z}_{\text {crítica }}= \pm 1.96\right)$ & Diferencia \\
\hline
\end{tabular}

Fuente: elaboración propia, con base en el INEGI (2015b).

Para Kunz-Bolaños y Romero-Vadillo (2008), con base en criterios de la Coordinación General del Plan Nacional de Zonas Deprimidas y Grupos Marginados, una vivienda sobrepasa su vida útil a partir de los 50 años, y es necesaria su reposición pues los materiales de construcción rebasan su vida media útil. Existe una diferencia significativa en los porcentajes de las viviendas de más de 50 años en el país y en la FNM, el promedio fue menor para la frontera (véase Figura 10).

El rezago cuantitativo incluye también los cuartos redondos, es decir, las viviendas que carecen de baño y cocina (Kunz-Bolaños y Romero-Vadillo 2008); ambos aspectos se abordan en este artículo, pero se analizan por separado. Así, las viviendas sin cocina no necesariamente corresponden a las que carecen de excusado y viceversa. Según el INEGI (2011), la privación de cocina se traduce en un déficit de espacio, pues los habitantes cocinan en el exterior, en techumbres o no lo hacen. El porcentaje de viviendas que no cuentan con un cuarto dispuesto para preparar o calentar alimentos, aunque también tenga otros usos (según la clasificación de cocina del INEGI), es mayor 
Figura 10. Antigüedad de la vivienda (\%), 2014

\begin{tabular}{|c|c|c|c|c|}
\hline Años & México & $\begin{array}{c}\text { Frontera } \\
\text { norte }\end{array}$ & Prueba de hipótesis & $\begin{array}{c}\text { Significancia } \\
\text { estadística }\end{array}$ \\
\hline 50 o menos & 96.9 & 97.5 & $\left(\mathrm{z}_{\text {calculada }}=-2.72, \mathrm{z}_{\text {crítica }}= \pm 1.96\right)$ & Diferencia \\
\hline Más de 50 & 3.1 & 2.5 & $\left(\mathrm{z}_{\text {calculada }}=2.72, \mathrm{z}_{\text {crítica }}= \pm 1.96\right)$ & Diferencia \\
\hline $\begin{array}{c}\text { No } \\
\text { especificado }\end{array}$ & 0.1 & 0.0 & $\left(\mathrm{z}_{\text {calculada }}=2.66, \mathrm{z}_{\text {crítica }}= \pm 1.96\right)$ & Diferencia \\
\hline
\end{tabular}

Fuente: elaboración propia, con base en el INEGI (2015b).

en México que en la FNM; la misma tendencia se observó en cuanto al excusado. Carecer de un sistema de tuberías de drenaje es un riesgo sanitario y de contaminación para el medio ambiente, ya que se usan fosas sépticas y desagües directos a ríos y mares, entre otros. Se probó una diferencia en las proporciones de viviendas que no tienen excusado entre la FNM y el resto del país (véase Figura 11).

Figura 11.Viviendas según carencia de cocina o excusado (\%), 2014

\begin{tabular}{|c|c|c|c|c|}
\hline Categoría & México & $\begin{array}{c}\text { Frontera } \\
\text { norte }\end{array}$ & Prueba de hipótesis & $\begin{array}{c}\text { Significancia } \\
\text { estadística }\end{array}$ \\
\hline $\begin{array}{c}\text { No tiene } \\
\text { cocina }\end{array}$ & 6.6 & 2.4 & $\left(\mathrm{z}_{\text {calculada }}=4.26, \mathrm{z}_{\text {crítica }}= \pm 1.96\right)$ & Diferencia \\
\hline $\begin{array}{c}\text { No tiene } \\
\text { excusado }\end{array}$ & 2.7 & 1.0 & $\left(\mathrm{z}_{\text {calculada }}=2.67, \mathrm{z}_{\text {crítica }}= \pm 1.96\right)$ & Diferencia \\
\hline
\end{tabular}

Fuente: elaboración propia, con base en el INEGI (2015b). 


\section{Déficit cualitativo}

Para analizar el rezago cualitativo se toma en cuenta la carencia en los espacios, servicios y materiales de construcción, que definen la vivienda como un bien que brinda protección a sus habitantes, y propicia un ambiente saludable e higiénico para el desarrollo de las actividades diarias. Implica que se debe evaluar según el supuesto de la salvaguarda, por ejemplo del clima, las inclemencias del medio ambiente o las condiciones insalubres.

\section{Espacios}

El concepto de hacinamiento se contrapone a la condición de contar con los espacios apropiados que deben brindar las viviendas, para que sus residentes realicen de manera adecuada sus tareas cotidianas; comer y dormir son las identificables, no así la recreación y la socialización. El criterio de hacinamiento de la Organización de las Naciones Unidas (citada en Palomares 2008) es hasta de 2.5 personas por habitación. El promedio de personas que viven en cada vivienda en la frontera es menor que en el resto del país, 3.6 y 3.9 respectivamente. El número promedio de cuartos usados habitualmente para

Figura 12.Viviendas según hacinamiento (\%), 2014

\begin{tabular}{|c|c|c|c|c|}
\hline \multirow{2}{*}{$\begin{array}{l}\text { Cuartos } \\
\text { para } \\
\text { dormir }\end{array}$} & \multicolumn{2}{|c|}{$\begin{array}{l}\text { Más de } 2.5 \text { personas } \\
\text { por dormitorio }\end{array}$} & \multirow{2}{*}{ Prueba de hipótesis } & \multirow{2}{*}{$\begin{array}{l}\text { Significancia } \\
\text { estadística }\end{array}$} \\
\hline & México & $\begin{array}{l}\text { Frontera } \\
\text { norte }\end{array}$ & & \\
\hline 1 & 57.5 & 47.7 & $\left(z_{\text {calculada }}=15.38, z_{\text {crítica }}= \pm 1.96\right)$ & Diferencia \\
\hline 2 & 11.3 & 9.7 & $\left(\mathrm{z}_{\text {calculada }}=3.96, \mathrm{z}_{\text {crítica }}= \pm 1.96\right)$ & Diferencia \\
\hline 3 & 3.4 & 2.0 & $\left(\mathrm{z}_{\text {calculada }}=6.19, \mathrm{z}_{\text {crítica }}= \pm 1.96\right)$ & Diferencia \\
\hline 4 & 0.8 & 0.5 & $\left(\mathrm{z}_{\text {calculada }}=2.69, \mathrm{z}_{\text {crítica }}= \pm 1.96\right)$ & Diferencia \\
\hline 5 o más & 0.2 & 0.0 & $\left(\mathrm{z}_{\text {calculada }}=3.77, \mathrm{z}_{\text {crítica }}= \pm 1.96\right)$ & Diferencia \\
\hline
\end{tabular}

Fuente: elaboración propia, con base en el INEGI (2015b). 
dormir, aunque tengan otros usos, sin contar pasillos y baños, es 4.1 en la FNM y 3.8 en el país. El porcentaje de viviendas con más hacinamiento en un solo cuarto para dormir en México fue de 57.5 por ciento, y de 47.7 en la FNM. En el resto del análisis de esta variable (2, 3, 4 y 5 o más dormitorios) tuvo la misma tendencia, con una confianza estadística de 95 por ciento para cada una de las categorías (véase Figura 12).

Lo que Kunz-Bolaños y Romero-Vadillo (2008) denominan diferenciación de espacios se refiere a las viviendas sin cocina ni baño exclusivo. En el caso de la cocina, significa que también se utiliza de manera habitual para dormir, mientras que el sanitario se refiere al uso compartido de la instalación con los habitantes de otra vivienda (INEGI 2011). En México y la FNM no hay diferencias significativas en el porcentaje promedio de viviendas que no tienen cocina exclusiva para preparar alimentos. En cambio, sí la hay en relación con el servicio exclusivo del sanitario (véase Figura 13).

Figura 13. Viviendas según diferenciación de espacios (\%), 2014

\begin{tabular}{|c|c|c|c|c|}
\hline Categoría & México & $\begin{array}{c}\text { Frontera } \\
\text { norte }\end{array}$ & Prueba de hipótesis & $\begin{array}{c}\text { Significancia } \\
\text { estadística }\end{array}$ \\
\hline $\begin{array}{c}\text { Sin cocina } \\
\text { exclusiva }\end{array}$ & 6.2 & 6.1 & $\left(\mathrm{z}_{\text {calculada }}=0.32, \mathrm{z}_{\text {crítica }}= \pm 1.96\right)$ & No diferencia \\
\hline $\begin{array}{c}\text { Sin servicio } \\
\text { sanitario } \\
\text { exclusivo }\end{array}$ & 7.6 & 4.6 & $\left(\mathrm{z}_{\text {calculada }}=9.04, \mathrm{z}_{\text {crítica }}= \pm 1.96\right)$ & Diferencia \\
\hline
\end{tabular}

Fuente: elaboración propia, con base en el INEGI (2015b).

\section{Servicios}

Las formas de abastecimiento de agua en la vivienda implican condiciones de salubridad. Carecer de agua entubada es un riesgo para la salud, puede ocasionar enfermedades diarreicas, cutáneas y oculares (INEGI 2011). Con base en estos criterios, el servicio de abasteci- 
miento de agua sólo es satisfactorio si es por tuberías, ya sea que la reciban entubada dentro o fuera de la vivienda pero dentro del terreno. Todas las categorías analizadas marcan carencias en este servicio, pero son dos las que tienen diferencias significativas; sus porcentajes son mayores en las viviendas del país que en la FNM (véase Figura 14).

Figura 14. Disponibilidad de agua (\%), 2014

\begin{tabular}{|c|c|c|c|c|}
\hline Categoría & México & $\begin{array}{c}\text { Frontera } \\
\text { norte }\end{array}$ & Prueba de hipótesis & $\begin{array}{c}\text { Significancia } \\
\text { estadística }\end{array}$ \\
\hline $\begin{array}{c}\text { Agua } \\
\text { entubada }\end{array}$ & 92.3 & 96.8 & $\left(\mathrm{z}_{\text {calculada }}=-13.67, \mathrm{z}_{\text {crítica }}= \pm 1.96\right)$ & Diferencia \\
\hline $\begin{array}{c}\text { Captadores de } \\
\text { agua de lluvia }\end{array}$ & 0.2 & 0.1 & $\left(\mathrm{z}_{\text {calculada }}=1.80, \mathrm{z}_{\text {crítica }}= \pm 1.96\right)$ & $\begin{array}{c}\text { No } \\
\text { diferencia }\end{array}$ \\
\hline $\begin{array}{c}\text { Agua entubada } \\
\text { que se acarrea } \\
\text { de otra } \\
\text { vivienda }\end{array}$ & 0.9 & 0.5 & $\left(\mathrm{z}_{\text {calculada }}=3.40, \mathrm{z}_{\text {crítica }}= \pm 1.96\right)$ & Diferencia \\
\hline $\begin{array}{c}\text { Agua de pipa } \\
\text { Agua de un } \\
\text { pozo, río, lago, } \\
\text { arroyo u otra }\end{array}$ & 1.6 & 1.4 & $\left(\mathrm{z}_{\text {calculada }}=1.24, \mathrm{z}_{\text {crítica }}= \pm 1.96\right)$ & $\begin{array}{c}\text { No } \\
\text { diferencia }\end{array}$ \\
\hline $\begin{array}{c}\text { Aroyoncia } \\
\text { Diferencia }\end{array}$ & $\left(\mathrm{z}_{\text {calculada }}=14.60, \mathrm{z}_{\text {crítica }}= \pm 1.96\right)$ & Dif \\
\hline
\end{tabular}

Fuente: elaboración propia, con base en el INEGI (2015b).

En la Figura 15 se muestra el destino del drenaje, en la evaluación de este servicio sólo las dos primeras categorías son satisfactorias, y las tres restantes deficitarias, pues utilizan otros métodos para desalojar los desechos humanos y las aguas utilizadas consideradas insalubres. 
Figura 15. Destino de drenaje (\%), 2014

\begin{tabular}{|c|c|c|c|c|}
\hline Categoría & México & $\begin{array}{c}\text { Frontera } \\
\text { norte }\end{array}$ & Prueba de hipótesis & $\begin{array}{c}\text { Significancia } \\
\text { estadística }\end{array}$ \\
\hline Red pública & 76.2 & 85.9 & $\left(\mathrm{z}_{\text {calculada }}=-18.07, \mathrm{z}_{\text {crítica }}= \pm 1.96\right)$ & Diferencia \\
\hline Fosa séptica & 16.5 & 9.2 & $\left(\mathrm{z}_{\text {calculada }}=15.70, \mathrm{z}_{\text {crítica }}= \pm 1.96\right)$ & Diferencia \\
\hline $\begin{array}{c}\text { Tubería que va } \\
\text { a una barranca } \\
\text { o grieta }\end{array}$ & 0.9 & 0.3 & $\left(\mathrm{z}_{\text {calculada }}=5.20, \mathrm{z}_{\text {crítica }}= \pm 1.96\right)$ & Diferencia \\
\hline $\begin{array}{c}\text { Tubería que va } \\
\text { a un río, lago } \\
\text { o mar }\end{array}$ & 0.6 & 0.1 & $\left(\mathrm{z}_{\text {calculada }}=5.38, \mathrm{z}_{\text {crítica }}= \pm 1.96\right)$ & Diferencia \\
\hline No tiene drenaje & 5.9 & 4.5 & $\left(\mathrm{z}_{\text {calculada }}=4.69, \mathrm{z}_{\text {crítica }}= \pm 1.96\right)$ & Diferencia \\
\hline
\end{tabular}

Fuente: elaboración propia, con base en el INEGI (2015b).

En cuanto a la eliminación de basura, hacerlo mediante un camión o carrito se considera un servicio adecuado, el resto de las categorías constituyen un déficit, representan carencia del servicio (véase Figura 16). Las tres categorías que constituyen una excepción, porque no hay diferencias significativas entre las dos zonas son las que tiran la basura en un terreno baldío o en la calle; en una barranca o grieta o a un río, lago o mar.

Figura 16. Eliminación de la basura (\%), 2014

\begin{tabular}{|c|c|c|c|c|}
\hline Categoría & México & $\begin{array}{c}\text { Frontera } \\
\text { norte }\end{array}$ & Prueba de hipótesis & $\begin{array}{c}\text { Significancia } \\
\text { estadística }\end{array}$ \\
\hline $\begin{array}{c}\text { La recoge un } \\
\text { camión } \\
\text { o carrito }\end{array}$ & 83.2 & 89.4 & $\left(\mathrm{z}_{\text {calculada }}=-13.17, \mathrm{z}_{\text {crítica }}= \pm 1.96\right)$ & Diferencia \\
\hline $\begin{array}{c}\text { La tiran en el } \\
\text { basurero público }\end{array}$ & 1.3 & 0.9 & $\left(\mathrm{z}_{\text {calculada }}=2.80, \mathrm{z}_{\text {crítica }}= \pm 1.96\right)$ & Diferencia \\
\hline $\begin{array}{c}\text { La tiran en un } \\
\text { contenedor o } \\
\text { depósito }\end{array}$ & 3.2 & 2.4 & $\left(\mathrm{z}_{\text {calculada }}=3.59, \mathrm{z}_{\text {crítica }}= \pm 1.96\right)$ & Diferencia \\
\hline
\end{tabular}


Continuación de Figura 16

\begin{tabular}{|c|c|c|c|c|}
\hline La queman & 11.2 & 6.7 & $\left(\mathrm{z}_{\text {calculada }}=11.38, \mathrm{z}_{\text {crítica }}= \pm 1.96\right)$ & Diferencia \\
\hline La entierran & 0.5 & 0.1 & $\left(\mathrm{z}_{\text {calculada }}=4.69, \mathrm{z}_{\text {crítica }}= \pm 1.96\right)$ & Diferencia \\
\hline $\begin{array}{c}\text { La tiran en un } \\
\text { terreno baldío o } \\
\text { calle }\end{array}$ & 0.4 & 0.3 & $\left(\mathrm{z}_{\text {calculada }}=1.25, \mathrm{z}_{\text {crítica }}= \pm 1.96\right)$ & No diferencia \\
\hline $\begin{array}{c}\text { La tiran en la } \\
\text { barranca } \\
\text { o grieta }\end{array}$ & 0.2 & 0.1 & $\left(\mathrm{z}_{\text {calculada }}=1.80, \mathrm{z}_{\text {crítica }}= \pm 1.96\right)$ & No diferencia \\
\hline $\begin{array}{c}\text { La tiran al río, } \\
\text { lago o mar }\end{array}$ & 0.0 & 0.0 & $\left(\mathrm{z}_{\text {calculada }}=0, \mathrm{z}_{\text {crítica }}= \pm 1.96\right)$ & No diferencia \\
\hline
\end{tabular}

Fuente: elaboración propia, con base en el INEGI (2015b).

En la no disponibilidad de energía eléctrica en las viviendas, proveniente del servicio público, de una planta particular, de panel solar o de otra fuente no hay diferencias significativas entre el país y la FNM. ${ }^{6}$ Cocinar o calentar los alimentos con leña, carbón u otro tipo de combustible que no sea gas y electricidad se consideró como carencia (véase Figura 17).

Figura 17. Tipo de combustible (\%), 2014

\begin{tabular}{|c|c|c|c|c|}
\hline Categoría & México & $\begin{array}{c}\text { Frontera } \\
\text { norte }\end{array}$ & Prueba de hipótesis & $\begin{array}{c}\text { Significancia } \\
\text { estadística }\end{array}$ \\
\hline Gas de tanque & 76.2 & 73.8 & $\left(\mathrm{z}_{\text {calculada }}=4.35, \mathrm{z}_{\text {crítica }}= \pm 1.96\right)$ & Diferencia \\
\hline $\begin{array}{c}\text { Gas natural } \\
\text { o de tubería }\end{array}$ & 6.8 & 20.8 & $\left(\mathrm{z}_{\text {calculada }}=-38.06, \mathrm{z}_{\text {crítica }}= \pm 1.96\right)$ & Diferencia \\
\hline Electricidad & 0.6 & 0.7 & $\left(\mathrm{z}_{\text {calculada }}=-0.99, \mathrm{z}_{\text {crítica }}= \pm 1.96\right)$ & No diferencia \\
\hline Leña & 15.6 & 4.5 & $\left(\mathrm{z}_{\text {calculada }}=24.90, \mathrm{z}_{\text {crítica }}= \pm 1.96\right)$ & Diferencia \\
\hline Carbón & 0.3 & 0.1 & $\left(\mathrm{z}_{\text {calculada }}=2.99, \mathrm{z}_{\text {crítica }}= \pm 1.96\right)$ & Diferencia \\
\hline Otro combustible & 0.5 & 0.1 & $\left(\mathrm{z}_{\text {calculada }}=4.69, \mathrm{z}_{\text {crítica }}= \pm 1.96\right)$ & Diferencia \\
\hline
\end{tabular}

Fuente: elaboración propia, con base en el INEGI (2015b).

$6 \quad\left(\mathrm{z}_{\text {calculada }}=1.22, \mathrm{z}_{\text {crítica }}= \pm 1.96\right)$. 


\section{Materiales de construcción}

Las características de los materiales de construcción de las viviendas, como los de las paredes, los pisos y los techos representan su resistencia constructiva ante los efectos adversos del medio ambiente (INEGI 2011). Los materiales como tabique, ladrillo, block, piedra, cantera o concreto y adobe se excluyeron del análisis de carencia; el resto no brinda la protección adecuada (véase Figura 18).

Figura 18. Material de paredes (\%), 2014

\begin{tabular}{|c|c|c|c|c|}
\hline Categoría & México & $\begin{array}{c}\text { Frontera } \\
\text { norte }\end{array}$ & Prueba de hipótesis & $\begin{array}{c}\text { Significancia } \\
\text { estadística }\end{array}$ \\
\hline $\begin{array}{c}\text { Tabique, ladrillo, } \\
\text { block, piedra, } \\
\text { cantera o } \\
\text { concreto }\end{array}$ & 88.6 & 86.2 & $\left(\mathrm{z}_{\text {calculada }}=5.77, \mathrm{z}_{\text {crítica }}= \pm 1.96\right)$ & Diferencia \\
\hline Madera & 3.9 & 5.3 & $\left(z_{\text {calculada }}=-5.46, z_{\text {crítica }}= \pm 1.96\right)$ & Diferencia \\
\hline Adobe & 5.8 & 7.2 & $\left(\mathrm{z}_{\text {calculada }}=-4.56, \mathrm{z}_{\text {crítica }}= \pm 1.96\right)$ & Diferencia \\
\hline $\begin{array}{l}\text { Material de } \\
\text { desecho }\end{array}$ & 0.3 & 0.5 & $\left(\mathrm{z}_{\text {calculada }}=2.70, \mathrm{z}_{\text {crítica }}= \pm 1.96\right)$ & Diferencia \\
\hline Lámina de cartón & 0.2 & 0.1 & $\left(\mathrm{z}_{\text {calculada }}=1.80, \mathrm{z}_{\text {crítica }}= \pm 1.96\right)$ & No diferencia \\
\hline $\begin{array}{l}\text { Lámina de } \\
\text { asbesto } \\
\text { o metálica }\end{array}$ & 0.6 & 0.3 & $\left(\mathrm{z}_{\text {calculada }}=3.13, \mathrm{z}_{\text {crítica }}= \pm 1.96\right)$ & Diferencia \\
\hline $\begin{array}{c}\text { Carrizo, bambú } \\
\text { o palma }\end{array}$ & 0.3 & 0.1 & $\left(\mathrm{z}_{\text {calculada }}=2.99, \mathrm{z}_{\text {crítica }}= \pm 1.96\right)$ & Diferencia \\
\hline $\begin{array}{l}\text { Embarro o } \\
\text { bajareque }\end{array}$ & 0.4 & 0.3 & $\left(\mathrm{z}_{\text {calculada }}=1.25, \mathrm{z}_{\text {crítica }}= \pm 1.96\right)$ & No diferencia \\
\hline
\end{tabular}

Fuente: elaboración propia, con base en el INEGI (2015b).

Los materiales utilizados en los techos, clasificados como carencias, fueron los de desecho, las láminas de cartón, metálica o de asbesto (véase Figura 19). 
Figura 19. Material de techos (\%), 2014

\begin{tabular}{|c|c|c|c|c|}
\hline Categoría & México & $\begin{array}{c}\text { Frontera } \\
\text { norte }\end{array}$ & Prueba de hipótesis & $\begin{array}{l}\text { Significancia } \\
\text { estadística }\end{array}$ \\
\hline $\begin{array}{c}\text { Losa de concreto } \\
\text { o viguetas } \\
\text { con bovedilla }\end{array}$ & 75.3 & 73.6 & $\left(\mathrm{z}_{\text {calculada }}=3.04, \mathrm{z}_{\text {crítica }}= \pm 1.96\right)$ & Diferencia \\
\hline $\begin{array}{c}\text { Lámina de } \\
\text { fibrocemento } \\
\text { ondulada } \\
\text { (techo fijo) }\end{array}$ & 0.1 & 0.1 & $\left(\mathrm{z}_{\text {calculada }}=0, \mathrm{z}_{\text {crítica }}= \pm 1.96\right)$ & $\begin{array}{c}\text { No } \\
\text { diferencia }\end{array}$ \\
\hline Palma o paja & 0.4 & 0.3 & $\left(\mathrm{z}_{\text {calculada }}=1.25, \mathrm{z}_{\text {crítica }}= \pm 1.96\right)$ & $\begin{array}{c}\text { No } \\
\text { diferencia }\end{array}$ \\
\hline $\begin{array}{l}\text { Madera o } \\
\text { tejamanil }\end{array}$ & 2.3 & 11.2 & $\left(\mathrm{z}_{\text {calculada }}=-36.75, \mathrm{z}_{\text {crítica }}= \pm 1.96\right)$ & Diferencia \\
\hline $\begin{array}{c}\text { Terrado } \\
\text { con viguería }\end{array}$ & 0.5 & 1.0 & $\left(z_{\text {calculada }}=-5.12, z_{\text {crítica }}= \pm 1.96\right)$ & Diferencia \\
\hline Teja & 2.2 & 0.1 & $\left(\mathrm{z}_{\text {calculada }}=12.0, \mathrm{z}_{\text {crítica }}= \pm 1.96\right)$ & Diferencia \\
\hline $\begin{array}{c}\text { Material } \\
\text { de desecho }\end{array}$ & 0.3 & 0.8 & $\left(\mathrm{z}_{\text {calculada }}=-6.33, \mathrm{z}_{\text {crítica }}= \pm 1.96\right)$ & Diferencia \\
\hline $\begin{array}{l}\text { Lámina de } \\
\text { cartón }\end{array}$ & 1.2 & 0.4 & $\left(\mathrm{z}_{\text {calculada }}=6.01, \mathrm{z}_{\text {crítica }}= \pm 1.96\right)$ & Diferencia \\
\hline Lámina metálica & 13.0 & 12.0 & $\left(\mathrm{z}_{\text {calculada }}=0.68, \mathrm{z}_{\text {crítica }}= \pm 1.96\right)$ & $\begin{array}{c}\text { No } \\
\text { diferencia }\end{array}$ \\
\hline $\begin{array}{c}\text { Lámina } \\
\text { de asbesto }\end{array}$ & 4.7 & 0.5 & $\left(\mathrm{z}_{\text {calculada }}=16.52, \mathrm{z}_{\text {crítica }}= \pm 1.96\right)$ & Diferencia \\
\hline
\end{tabular}

Fuente: elaboración propia, con base en el INEGI (2015b).

La carencia en materiales de construcción en pisos se expresa en los de tierra (véase Figura 20). Las viviendas de México utilizan más piso de tierra (3.0 por ciento), que en la FNM (1.3). 
Figura 20. Material de pisos (\%), 2014

\begin{tabular}{|c|c|c|c|c|}
\hline Categoría & México & $\begin{array}{c}\text { Frontera } \\
\text { norte }\end{array}$ & Prueba de hipótesis & $\begin{array}{c}\text { Significancia } \\
\text { estadística }\end{array}$ \\
\hline $\begin{array}{c}\text { Cemento } \\
\text { o firme }\end{array}$ & 52.7 & 45.9 & $\left(\mathrm{z}_{\text {calculada }}=10.55, \mathrm{z}_{\text {crítica }}= \pm 1.96\right)$ & Diferencia \\
\hline $\begin{array}{c}\text { Madera, } \\
\text { mosaico } \\
\text { u otro } \\
\text { recubrimiento }\end{array}$ & 44.3 & 52.8 & $\left(\mathrm{z}_{\text {calculada }}=-13.24, \mathrm{z}_{\text {crítica }}= \pm 1.96\right)$ & Diferencia \\
\hline Tierra & 3.0 & 1.3 & $\left(\mathrm{z}_{\text {calculada }}=-11.55, \mathrm{z}_{\text {crítica }}= \pm 1.96\right)$ & Diferencia \\
\hline
\end{tabular}

Fuente: elaboración propia, con base en el INEGI (2015b).

\section{Satisfacción residencial}

La evaluación de la vivienda se examina con dos variables, incluidas en el cuestionario del BIARE; la satisfacción con ésta y con el vecindario. La pregunta ¿qué tan satisfecho está con su vivienda?, utiliza una métrica de respuesta de 0 a 10 ; totalmente insatisfecho es 0 y 10 es totalmente satisfecho (véase Figura 21).

Figura 21. Satisfacción con la vivienda (escala 0-10), 2014

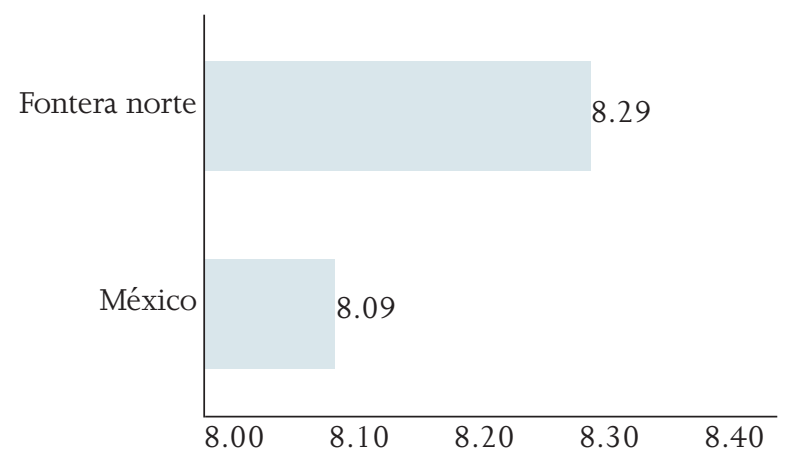

Nota: $(\mathrm{t}=-7.78, \mathrm{p}>0.05)$.

Fuente: elaboración propia, con base en el INEGI (2015b). 
Al catalogar las respuestas 9 y 10 como muy satisfechas, 7 y 8 satisfechas, 6 y 5 insatisfechas y de 4 a 0 como muy insatisfechas, ${ }^{7}$ el porcentaje de muy satisfechos con su vivienda es mayor en la frontera norte que en el país, y los de insatisfechos o muy insatisfechos son menores en dicha zona (véase Figura 22).

Figura 22. Porcentaje de la población según categoría de satisfacción con la vivienda, 2014

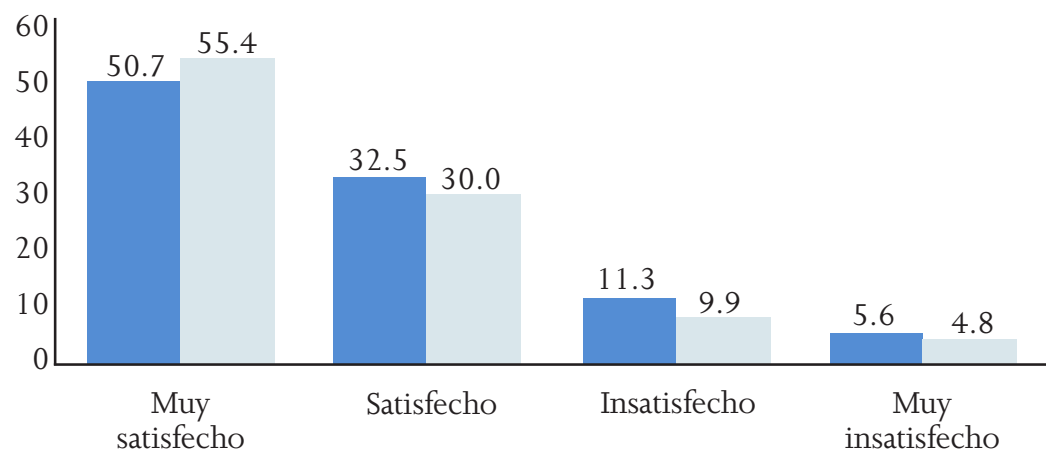

México Fontera norte

Nota: "muy satisfecho" $\left(\mathrm{z}_{\text {calculada }}=-7.29, \mathrm{z}_{\text {crítica }}= \pm 1.96\right)$; “satisfecho" $\left(\mathrm{z}_{\text {calculada }}=4.15, \mathrm{z}_{\text {críti- }}\right.$ ca $= \pm 1.96)$; "insatisfecho" ( $\left.\mathrm{z}_{\text {calculada }}=7.90, \mathrm{z}_{\text {crítica }}= \pm 1.96\right)$; "muy insatisfecho" $\left(\mathrm{z}_{\text {calculada }}=2.72\right.$, $\left.\mathrm{z}_{\text {crítica }}= \pm 1.96\right)$.

Fuente: elaboración propia, con base en el INEGI (2015b).

También existe diferencia significativa entre la población de la FNM y del país, cuando se preguntó ¿qué tan satisfecho está con su vecindario? (véase Figura 23).

7 Esta clasificación la utiliza el INEGI para presentar el indicador de satisfacción con la vida, con la misma métrica de 0 a 10. 
Figura 23. Satisfacción con el vecindario (escala 0-10), 2014

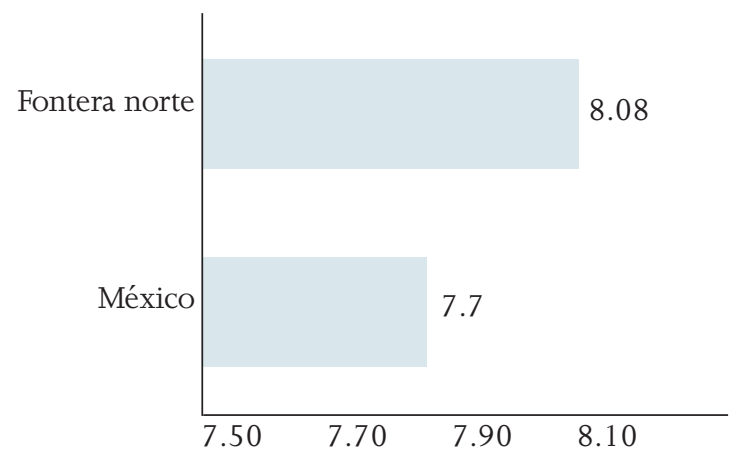

Nota: $(\mathrm{t}=-11.79, \mathrm{p}>0.05)$.

Fuente: elaboración propia, con base en el INEGI (2015b).

En las cuatro categorías en que se clasificó la satisfacción con el vecindario y con la vivienda se observaron las mismas tendencias. Asimismo, en la frontera se presentan los menores porcentajes en las categorías de insatisfecho y muy insatisfecho con su vivienda (véase Figura 24).

Figura 24. Porcentaje de la población según categoría de satisfacción con el vecindario, 2014

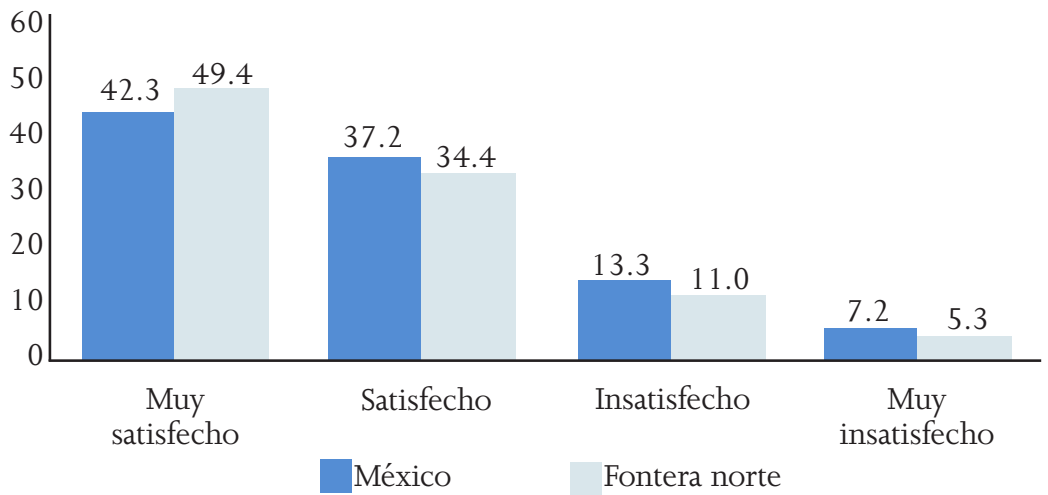

Nota: "muy satisfecho" $\left(\mathrm{z}_{\text {calculada }}=-11.11, \mathrm{z}_{\text {crítica }}= \pm 1.96\right)$; "satisfecho" $\left(\mathrm{z}_{\text {calculada }}=4.50, \mathrm{z}_{\text {críti- }}\right.$ $\mathrm{ca}= \pm 1.96)$; "insatisfecho" $\left(\mathrm{z}_{\text {calculada }}=5.31, \mathrm{z}_{\text {crítica }}= \pm 1.96\right)$; "muy insatisfecho" $\left(\mathrm{z}_{\text {calculada }}=5.81\right.$, $\left.\mathrm{z}_{\text {crítica }}= \pm 1.96\right)$.

Fuente: elaboración propia, con base en el INEGI (2015b). 


\section{Resultados}

Del total de aspectos analizados en la evaluación del déficit de vivienda y satisfacción residencial, los resultados fueron mejores para la frontera norte que para el país. En relación con el déficit cuantitativo, que incluye seis aspectos, existe mayor porcentaje de familias que no cuentan con casa propia en México que en la FNM, además hay mayor proporción de viviendas con más de 50 años en México que en la frontera norte. También la carencia de cocina y de excusado sigue la misma tendencia. Sin embargo, no hubo diferencias en los porcentajes de las viviendas en cuarto de azotea, así como en locales no construidos para habitación.

En los tres aspectos considerados en el análisis del déficit cualitativo, en el relativo al espacio fue mayor el porcentaje de viviendas con hacinamiento en México que en la zona fronteriza; fueron más de 2.5 habitantes por dormitorio. Por otro lado, no hubo diferencias en el promedio de viviendas sin cocina exclusiva para preparar alimentos, pero sí en el servicio exclusivo del sanitario, a favor de la frontera norte.

El segundo aspecto analizado fue la disponibilidad de servicios. En el abastecimiento de agua, dos de las categorías presentaron porcentajes menores de carencia en la frontera, y en uno hubo diferencias entre las dos zonas.

El servicio de drenaje fue mejor en la franja fronteriza. De las siete categorías consideradas, en cuatro el porcentaje de carencias fue mayor en México que en la FNM. En la disponibilidad de energía eléctrica no hubo diferencias, y en el tipo de combustible utilizado para preparar o calentar alimentos en la vivienda, las carencias se presentan en mayores proporciones en el país que en la FNM.

El tercer aspecto del déficit cualitativo son los materiales de construcción, se definieron cinco tipos en las paredes, que reflejan carencias, de los cuales la lámina de cartón y el embarro o bajareque no presentan diferencias en los porcentajes de las viviendas entre México y la FNM. Los otros tres: lámina de asbesto o metálica, carrizo, bambú o palma son más utilizados en México, en cambio, el uso de los materiales de desecho en paredes fue más elevado en la frontera. 
En la FNM se utilizan más materiales de desecho en los techos, que en el país. En cambio, en más viviendas del resto de la república se empleaba, de forma predominante, la lámina de cartón o la de asbesto. Por último, los pisos de tierra se usaban más en México que en la frontera. Y fue mayor el promedio de satisfacción con la vivienda y con el vecindario entre los residentes de la franja fronteriza en relación con los del país.

\section{Conclusiones}

Para Kunz-Bolaños y Romero-Vadillo $(2008,416)$, las estimaciones oficiales del problema del déficit de la vivienda en México son "excesivamente moderadas". Se busca ocultar la incapacidad del Estado para resolver esta problemática, debida a la incompetencia de los encargados y hacedores de las políticas; por lo tanto, se tiende a presentar sólo una parte de la dimensión verdadera de la realidad.

Los resultados de este artículo ofrecen un escenario que debe ubicarse en el contexto habitacional del país, donde "la edificación de espacios adecuados de convivencia social al alcance de las posibilidades de la gran mayoría de las familias es uno de los problemas aún no resueltos" (Palomares 2008, 160). Para este autor, la urbanización en México está acompañada del incremento de las actividades terciarias, donde los patrones de construcción y las políticas de desarrollo de complejos habitacionales colocan el acondicionamiento de la vivienda como algo secundario. Como consecuencia, en los últimos años se han reducido los espacios para unidades habitacionales de demanda masiva, en detrimento de la calidad de la construcción y los servicios de éstas.

El tema de la vivienda se distingue por la importancia de relacionar el déficit habitacional con las políticas públicas (Arriagada 2003), que permitan establecer acciones y los recursos necesarios para combatir esta problemática social. Según datos del Consejo Nacional de Organismos Estatales de Vivienda (CONOREVI 2011), en México se ha otorgado prioridad a los programas para la construcción y adquisición de viviendas nuevas, a los cuales se destinó 93 por ciento del total de los recursos invertidos en la década de 1990 y 96 por ciento 
en la siguiente; esto ha dejado de lado el financiamiento para hacer mejoras en las ya existentes que, según lo analizado aquí, encaja en el déficit cualitativo.

Considerar la demografía del país es importante para el diseño de las políticas habitacionales en México, pues ofrece información de los requerimientos nuevos en la materia. Se estima que para 2030 habrá 120928075 habitantes y 39193231 hogares, y según las proyecciones de la proporción de hogares respecto a la población total, entre 2010 y 2020 se requerirán 775 mil viviendas anuales, y 550 mil, de 2020 a 2030, lo que revela la necesidad de un diseño adecuado de la política habitacional (CONOREVI 2011).

Entre 2005 y 2010 , el crecimiento poblacional del país se sustentó en 402 municipios, que integran a las 115 ciudades sobresalientes, todos urbanos y con fuerte aporte al producto interno bruto. En contraste, en los otros 2039 municipios, mayormente rurales, hubo una caída de 7 por ciento, aspecto que muestra la necesidad de adecuar los esfuerzos en materia de políticas habitacionales. En este contexto, las evaluaciones regionales de la vivienda en las ciudades son de gran utilidad para los hacedores de políticas públicas. De los seis estados que componen la FNM, sólo Chihuahua y Baja California superaron el promedio nacional en relación con el rezago habitacional (CONOREVI 2011).

La evaluación del déficit habitacional y de la satisfacción residencial tanto en el país como en la FNM es útil para las políticas de vivienda. Guillén (2007) y Acosta et al. (2012) documentaron la relación entre el déficit y la calidad de la vivienda en la frontera norte, debido al intenso proceso de urbanización sobresale lo heterogéneo de los resultados. Sin embargo, los de la situación de la frontera fueron mejores en el déficit cuantitativo y cualitativo de vivienda, expresados en temas como el hacinamiento, carencia en servicios y espacios y materiales de construcción, entre otros. Asimismo, también en esta zona los habitantes expresaron más satisfacción con la vivienda y con el vecindario, temas que ofrecen un panorama más amplio en la evaluación, que buscan ampliar el conocimiento y fortalecer la idea de que la vivienda debe brindarles a sus ocupantes la posibilidad de lograr un desarrollo sano (Kunz-Bolaños y Romero-Vadillo 2008). Si bien dicho desarrollo comprende otros aspectos, en este artículo la 
satisfacción constituye un buen indicador valorativo que lo expresa, ya que incluye factores psicológicos y de apreciación de los habitantes.

Hay que profundizar en la investigación comparativa, sobre todo utilizar otros marcos como la condición rural-urbana o socioeconómica, que permitan ampliar el conocimiento del déficit y la satisfacción residencial, con el fin de influir en las políticas públicas de vivienda que busquen mejorar estos aspectos. Por ejemplo, el CONAVI (CONOREVI 2011) estima que en 2030, 41 por ciento de la población no será derechohabiente, es decir, cerca de la mitad de la demanda total de vivienda provendrá de dicho sector sin capacidad de pago.

\section{Bibliografía}

Acosta, Félix, Marlene Solís y Guillermo Alonso. 2012. Grado de apropiación de la ciudad y percepciones sobre la calidad de vida en ciudades de la frontera norte de México. Cofactor III (6): 11-42.

Andrade, Miguel, Carlos Aguirre y María Elena Mora. 2007. Antecedentes para una evaluación de la satisfacción residencial de los beneficiarios del Fondo Solidario de Vivienda (FSV). Revista de la Construcción 6 (2): 42-51.

Aragonés, Juan Ignacio y María Amérigo. 1987. Satisfacción residencial: un concepto de calidad de vida. Documentación Social (67): 133154.

Arriagada Luco, Camilo. 2003. América Latina: información y herramientas sociodemográficas para analizar y atender el déficit habitacional. Proyecto Regional de Población CELADE-UNFPA. Santiago de Chile: CEPAL.

Boils, Guillermo. 2004. Banco Mundial y la política de vivienda en México. Revista Mexicana de Sociología 66 (2): 345-367.

Boltvinik, Julio. 1992. El método de medición integrada de la pobreza. Una propuesta para su desarrollo. Comercio Exterior 42 (4): 354-365. 
CEPAL. 2014. Urbanización y políticas de vivienda en China y América Latina y el Caribe. Perspectivas y estudios de caso. Santiago de Chile: Organización de las Naciones Unidas.

CONEVAL. 2010. Carencia en la calidad y espacios de la vivienda. México: CONEVAL.

CONOREVI. 2011. La situación de la vivienda en México: síntesis de problemática y propuestas. México: CONOREVI.

Dávila, Alejandro. 2008. Los clusters industriales del noreste de México (1993-2003). Perspectivas de desarrollo en el marco de una mayor integración económica con Texas. región y sociedad 20 (41): 57-88. DOI: $10.22198 /$ rys.2008.41a518

González Ramírez, Raúl. 2013. La calidad de vida en Tijuana y Monterrey. Un estudio exploratorio-comparativo. Frontera Norte 25 (49): 109-129.

Guillén, Tonatiuh. 2007. Frontera norte: los contrastes de la calidad de vida. Revista Mexicana de Política Exterior 81: 9-32.

Hanson, Gordon H. 2003. What has happened to wages in Mexico since NAFTA? Implications for hemispheric free trade. NBER Working paper series: 1-43.

Ibarra Salazar, Jorge, José Salazar Cantú y José Polendo Garza. 2016. La satisfacción de residentes con su colonia y el programa gubernamental Tu Casa en el estado de Zacatecas. Estudios Demográficos y Urbanos 31 (2): 413-464.

INEGI. 2015a. Encuesta nacional de ingresos y gastos de los hogares (2014). Módulo de condiciones socioeconómicas: Encuesta nacional de ingresos y gastos de los hogares 2014: descripción de la base de datos/Instituto Nacional de Estadística y Geografía. México: INEGI. 
INEGI. 2015b. Encuesta nacional de ingresos y gastos de los hogares (2014). Módulo de condiciones socioeconómicas 2014: microdatos. Módulo de bienestar autorreportado 2014: microdatos. México: INEGI.

INEGI. 2011. Censo de población y vivienda (2010): marco conceptual / Instituto Nacional de Estadística y Geografía. México: INEGI.

Kunz-Bolaños, Ignacio e Irma Romero-Vadillo. 2008. Naturaleza y dimensión del rezago habitacional en México. Economía, Sociedad y Territorio VIII (26): 415-449.

Mendoza, Jorge. 2010. El mercado laboral en la frontera norte de México: estructura y políticas de empleo. Estudios Fronterizos nueva época II (21): 9-42.

Monkkonen, Paavo. 2009. The housing transition in Mexico: local impacts of national policy. Working paper D09 (001). Dissertation and thesis series.

Moyano Díaz, E. 2009. Satisfacción con la vivienda en conjuntos residenciales de cooperativas y su relación con variables del mesosistema. INVI (20): 3-15.

Palomares, Humberto. 2008. Acondicionamiento de la vivienda en áreas urbanas del norte de México. Frontera Norte 20 (39): 157-190.

SEDESOL. s/f. Programa de Desarrollo Regional Frontera Norte 2001 2006. México: SEDESOL.

Wenze, Xie. 2014. Transformación económica, social y política en los países latinoamericanos después de que el grado de urbanización alcanzó el 50\%. En Urbanización y políticas de vivienda en China y América Latina y el Caribe. Perspectivas y estudios de caso, de CEPAL, 95-146. Santiago de Chile: Organización de las Naciones Unidas. 